\title{
University Library Search and Screen Committees
}

\begin{abstract}
Current policies and practices of committees used in university libraries to search for and screen candidates for positions are described, primarily from responses to a survey conducted by the authors. The use of such committees is seen as one result of increasing staff participation in library administration; and their strengths and weaknesses are discussed.
\end{abstract}

C

IURRENTLY MANY AMERICAN UNIVERSITY LIBRARIES are turning over the responsibility of recruiting and selecting new professionals to search and screen committees, in contrast to the traditional university library personnel policies of either having supervisors recruit and select or having the staff members supervised recruit and elect their own supervisors. Such formally organized committees have been used widely for at least a generation to assist in filling university presidents' positions. Library search and screen committees are a recent phenomenon, however, perhaps one of the past five to ten years in which we have witnessed participatory library administration increasing.

Since literature on the subject is sparse, the growing popularity of search and screen committees suggests the appropriateness of a paper recommending guidelines and explaining options for use. While sparse, some search and screen committee literature does exist. An American Council on Education pamphlet provides a full description of

John F. Harvey is dean of library services, and Mary Parr is chairperson, periodicals department, Hofstra University Library, Hempstead, New York. the committee task and should be helpful to readers. ${ }^{1}$ A paper by Richard Sommerfeld and Donna Nagely is a useful committee operation manual, especially in explaining the reasons for this development and describing the pitfalls to avoid. ${ }^{2}$ The University of Louisville experience is common and can be used as a library model, but the Northwestern University experience is atypical and provides only a negative example. ${ }^{3,4}$ Paul G. Reinert stresses the slowness, expense, and complexity of these committees and the likelihood that their personnel decisions will involve campus politics. $^{5}$ Paul Strohm believes that search and screen committees should be named in consultation with relevant constituencies and that committee recommendations should not be overturned without additional consultation. ${ }^{6}$

Several universities have their own written library/faculty personnel selection policy and procedure statements which may be helpful for others to read, for example, Oakland, North Carolina, Maryland, and Minnesota. Letters received through a personal survey of current policy and practice in forty university libraries supplement the literature cited above. ${ }^{7}$

In common parlance a search commit- 
tee, a screening committee, and a search and screen committee are titles which suggest similar if not identical activities. Obviously, a search committee, narrowly conceived, may search and locate only, leaving candidate screening to others. A screening committee screens, rates, or evaluates the leading candidates located by the administrator, often in interview situations. In practice, however, both kinds of committees may carry out most or all of both responsibilities, as, of course, does the search and screen committee. A search and screen committee may allocate much work to its chairperson, but a screening committee can distribute work more equally among its members. The screening process may be used in simple form without a committee, also, as at Tennessee, where numerous staff members rate candidates found by the library administration. This paper will discuss both the search and screen ends of the task.

There is a body of opinion which addresses the difference between searching and screening and stresses the greater effectiveness of committee screening than of committee searching. Many large libraries fill a dozen vacancies a year and typically are conducting several searches simultaneously. A library personnel officer can handle the details of these searches and narrow the choice skillfully and efficiently. The complexities of library faculty searching in the 1970 s, with federal and campus affirmative action, equal opportunity, and additional requirements and voluminous correspondence and oral contacts, on campus and off, suggest that the burden of work and understanding will be much more onerous to a one-time-only search and screen committee chairperson than to a full-time personnel officer already well acquainted with the policies and routines involved.

Screening a limited number of wellqualified candidates, on the other hand, calls for the judgments of a variety of concerned persons and can better be handled by a committee. Of course, the library without a personnel officer is left with the need to carry out both ends of the task in another way.

The search and screen committee objective is to assist the library administration in filling a specific budgeted professional position vacancy with the best candidate available at the time. Most search and screen committees are expected to complete their work by presenting the administrator to whom they report with a list in alphabetical or priority order of the best available candidates. The salary required to hire each candidate may be requested also.

\section{Policies and Practices}

Many varying search and screen committee policies and practices are being used in American university libraries, and this paper will summarize them. On certain campuses only library directorships are filled through search and screen committee use, while on other campuses, e.g., University of New Mexico and University of Minnesota Twin Cities, all professional library vacancies are filled in this way. Still other campuses, e.g., New Mexico State University, University of North Carolina, and Columbia University, require such committee use in filling all professional vacancies above a certain rank.

In certain universities, even high-level support-staff vacancies may be filled through search and screen committee use. In contrast, probably a few libraries have used no search and screen committees. Each campus must work out its own policy for the level and circumstances of use.

\section{Committee Selection}

Committee member selection policies vary. Normally a new committee is appointed for each vacancy. Occasionally, a search and screen committee will be formed from the university's advisory 
faculty library committee with additions from the library staff. An advantage of regularly assigning search or screen responsibilities to the standing tenure and promotion committee is that this policy allows that group to carry out these chores for all vacancies and for the entire staff, thereby occupying the time of only a small group of people. Otherwise, university libraries using a separate committee for each vacancy may be quite weighed down with committee work.

In certain libraries, e.g., University of New Mexico, the library department with the vacancy insists on strong search committee representation, while in other libraries, e.g., Colorado State University, such representation is avoided. The same kind of disagreement may affect teaching faculty member use on the committee.

Who should choose search and screen committee members, and how should they be chosen? Normally, the library director will select the committee with advice from department heads and sometimes with the staff electing certain committee members. If a director is being sought, the university administrator to whom the director reports will choose the committee. Occasionally, entire search and screen committees are elected by the library or departmental staff members, as at Louisville.

Certain search and screen committees selected for specific vacancies and certain standing tenure and promotion committees are appointed through the university library's formally organized faculty assembly. This coordination provides the library faculty with a means of assisting the administration in carrying out its tasks. A few search and screen committees are large, eighteen or twenty for a major position, while others are small, perhaps only three members, as at Eastern New Mexico University. Certain administrators name the committee officers-chairper- son, vice-chairperson, and secretary; but others encourage the committee to elect its own, e.g., State University of New York at Albany. In searches to fill highlevel vacancies, the library director may serve as committee chairperson or secretary, though certain authorities frown on this practice since the director must then play a dual role.

The administrator appointing the search and screen committee will insure its success or failure by the wisdom of the appointments made, the choice of the chairperson being by far the most important of them. Generally, service as chairperson is considered to be an honor, sometimes even a campuswide honor when a major library position is being filled. This honor may go to a respected campus leader who is called upon to perform a public service for the university administration. The chairperson needs free time weekly for this assignment, as well as good access to secretarial help to carry out the large amount of correspondence and recordkeeping involved. Even committee membership is an honor and permits individuals to leave their desks for several hours each month to sit in closed conference with certain colleagues.

Search and screen committees may include university trustees, alumni, townspeople, and relevant campus committee representatives. Certain committees are selected carefully and democratically to represent many diverse groups, while others are selected solely from a few groups. Usually both sexes and sometimes both professional and supportstaff members are represented. In certain libraries, for instance, a readers service division chief search and screen committee might contain professionals and support-staff members who would work under this person; a technical services division staff member; a teaching faculty department chairperson; deans or professors whose library service this person would supervise; students; and a 
dean of students office staff member interested in the caliber of library service.

\section{Level of Responsibility}

Responsibility should accompany authority in staff selection, so the person supervising the vacancy should have an important responsibility in filling it. Just how this idea is carried out is not described in many of the responses received by the authors. Sometimes this person serves on the search and screen committee, while in other cases, he or she works closely with the administrator who collects candidate data. Final candidates may be cleared with this person before an offer is made.

Certain administrators give search and screen committees wide latitude and turn over most of the recruiting and selecting responsibility to them, while others use them only to rate and advise and not even to present a slate of recommended candidates. Some administrators ask committees to search nationally and internationally for a pool of position candidates, while others limit them to local or regional searches, depending on the vacancy level and the director's ambitions for the staff. In most cases, internal and external candidates are given equal consideration. Many administrators give committees deadlines for work completion. Most administrators appoint only from the committee's short list, while a few may appoint unlisted persons. Still other administrators insist that a decision be obtained on each candidate before the next one is considered.

\section{Meetings}

Certain administrators attend the search and screen committee's initial meeting in order to clarify the charge, policies, and procedures for the members. The currently appropriate and full position description, faculty rank, salary range, tenure status, affirmative action, and equal opportunity steps must be described. Deadlines and shortlist presentation information must be provided. The advisory nature of the committee recommendations and the appointment routine should also be described. Early in its work, the committee must clarify its budget. Correspondence, telephone calls, meals with candidates, and possible library school visits constitute its own expenses. Candidate expenses include travel, lodging, and meals when coming for an interview. Finally, if its role is to be carried out expeditiously, the committee must adopt a timetable for the project and a meeting schedule.

The committee should meet at least monthly, sometimes weekly. All members present should vote on all important matters. Meeting minutes should be sent to the members and the director. The committee should attempt to bring to the library the best-qualified and available candidates in the country, candidates capable of making significant contributions to library staff thinking on a variety of problems.

\section{Selecting Candidates}

The position description should clarify the relevant responsibilities, to whom the staff member reports, the qualifications required, and the salary and fringe benefits available. The description should show the number and level of staff members to be supervised or the amount of money to be spent. It will assist the committee in focusing on the best-qualified candidates and is usually prepared by the library administration.

The search for candidates should be intensive and extensive. A pool of candidate names may be collected in the following manner:

a. Obtaining suggestions from the directors of twenty-five or so large university libraries.

b. Writing to twenty-five or so library schools for candidate lists. 
c. Advertising in library periodicals, in scientific or other periodicals, in the Chronicle of Higher Education, the AAUP Academe, and the New York Times.

d. Advertising the vacancy and interviewing candidates at national conferences.

e. Notifying present library staff members who may wish to apply.

f. Notifying placement organizations established to assist minority persons and women.

g. Checking the library's file of unsolicited applications.

h. Writing to academic department chairpersons and faculty members, where appropriate.

Additional steps should include the compilation of dossiers for the best dozen or fifteen candidates. Each one should consist of a curriculum vitae, references, and other biographical material. Library school placement folders and transcribed telephone calls can be helpful. Furthermore, form letters, documentation of affirmative action, and extensive mailings will be needed. From the position description, advertisements, and announcements can be prepared.

An appropriate set of criteria should be developed against which all candidates can be rated. The most important characteristics to be sought in the person who fills the position should be stressed. Weights may be assigned to reflect the various factors' importance. The required data should be collected, the weighted criteria applied, and, if practical, a ranking derived for each candidate. A record must be kept of each candidate's evaluation and the reasons for rejection.

\section{Campus Interviews}

The top two to six candidates (the short list) should be brought to the campus for twelve- to forty-eight-hour visits to allow staff members to evaluate them. The top two candidates may be selected questions. Presumably, they should be invited in their quality order. The university administration may have estabfor repeat visits to clarify important lished budgetary and procedural regulations to guide the committee in entertaining and housing them.

Each candidate should be introduced to as large a number and as great a variety of campus persons as possible for mutually beneficial exposure. An itinerary should be given to the candidate and with a curriculum vitae supplied to all persons listed on it before his or her arrival. Library faculty and support-staff members, teaching faculty members, administrators, and students should be included. The library department heads' council, the faculty library committee, the entire departmental staff directly involved, student body officers, faculty senate officers, and library staff association officers should be represented in candidate meetings, luncheons, and interviews. The director and assistant directoor should see the candidate, and, on some campuses, the academic vicepresident will see the candidate as well.

Typically, an appointment is made with the tenure and promotion committee since the application of their criteria and interpretations to all candidates is appropriate and helpful. In addition, each candidate's weaknesses may be identified and a decision made about which set of weaknesses would be least problematic. Alerting candidates to special campus pressure groups, physical plant problems, and the concerns of those to be supervised, as well as longrange library plans, will provide needed orientation information. Regrettably, the contrast between the mannered politeness of the screening routine and the blunt political reality of the position has caused many directors anguish.

Each candidate may make a public presentation to a campus group on a topic of his or her own choosing or one 
related to the vacancy. This is simply another method of gauging the candidate's effectiveness. A packet of material about the institution and the library should be given to each candidate to provide further background information. Search and screen committees should be hospitable and friendly, but at the same time they must look at each candidate very critically and ask penetrating questions to gauge thinking. The committee should take the initiative in carrying out a thorough analysis of the candidate's personality, abilities, knowledge, and ideas while providing a full and honest picture of the local situation.

When the visit is concluded, each candidate should be evaluated in writing by each person who has met him or her. The completed evaluation forms should be collected by the committee and the degree of favorability scored. They should show the extent to which the candidate has met the position criteria.

The final list of the top three to five candidates should be sent to the administrator soon after the evaluations and committee votes are tabulated. With this step, the search and screen committee's work is done. Normally, the administrator will carry out final contract negotiations to hire the candidate.

\section{Strengths}

In many situations, the university library search and screen committee enjoys the following strengths:

1. In an era of participatory and consultative management, the search and screen committee provides a democratic method of recruiting and selecting new personnel. Often it reflects the relatively new faculty status of library professionals.

2. Some committees work quickly, efficiently, and intelligently and land their person in three months or less, e.g., University of New
Mexico's 1973 special collections chief search committee.

3. A search and screen committee provides well-informed and vitally involved persons to assist in recruiting and selecting new personnel.

4. Appointment of staff members to such a committee can provide useful information to the administrator concerning their skill and interest in administrative and committee work.

5. Often the search and screen committee is a useful supplement to a small and overworked library administrative staff.

6. In this way, a variety of opinions can be obtained on every position candidate, and the candidate is able to meet varied campus groups and ideas.

7. Many staff members enjoy serving on such committees, thereby escaping briefly the routine of daily work assignments.

8. "Political" recognition from staff and faculty members attracts other persons to this responsibility.

9. By using such committees for many vacancies, library administrators may reduce the upward mobility of their own staff members. Apparently, many search committees suffer from a bias against local candidates. The glamorous outsider about whom very little is known always looks better than the shopworn insider about whom too much is known. This may be an advantage or a disadvantage, depending upon local circumstances. On the other hand, in some circumstances the politically resourceful insider may turn the situation around and make the subtle pressures of staff opinion felt.

10. Library staff members participating actively in personnel selection 
display a greater sensitivity than before to the problems of locating high-quality position candidates.

11. The search and screen committee enables the library to involve other parts of the university, particularly the faculty, in its activity, even in its decision making. Such involvement should lead to improved knowledge and understanding and perhaps to closer alignment with other campus units.

12. No objective evidence was located concerning the superiority of the judgments made or the candidates appointed through search and screen committee use, as contrasted with more traditional or more democratic approaches. Nevertheless, most respondents felt such committee methods to be more successful than traditional administrative methods. Representative staff judgment and participation were felt to be beneficial to staff morale and confidence and to the new appointee who arrives with widespread recognition and support.

\section{WEAKNESSES}

In many university libraries, the weaknesses of search and screen committees seem to be the following:

1. The spirit with which the committee is appointed can be decisive. If it mainly represents "window dressing," or political expediency, then the committee is likely to fail. Bennis' article in the Atlantic provides one such example, ${ }^{8}$ as does a situation in which a candidate is appointed because he or she has developed a vocal and persuasive committee champion.

2. While some committees are perceptive and agree quickly on what they are doing, others are not and do not. Many search and screen committees seek the ideal individual and fail to set priorities among qualifications. Failure to appraise realistically the qualifications required by the position and demonstrated by the candidates creates many problems. Considerable disagreement may exist about ranking the various candidates and even about the very nature of the position itself. Expecting a great deal of sensitivity and thoroughness from such temporary appointees, however, may be naive.

3. Certain committees lack the knowledge, administrative ability, or interest to carry out the task satisfactorily. They muddle along with more discussion than action, hold irregular and poorly attended meetings, and are overwhelmed by the paperwork required. Still other committees are fatally attracted to the freeloading interview routine and eagerly run up large liquor and food bills at the best restaurants while interviewing second-rate candidates. Such a situation might force the library to fill the vacancy with an acting person for years at a time, e.g., the 1972-74 State University of New York at Stony Brook and the Hofstra University Library directorships.

4. Strange things have happened on search and screen committees: (a) occasional sets of candidate papers have been lost, and (b) some committees have deliberately sought candidates less well qualified than the predecessor!

5. On certain campuses, committees are chosen, at least in part, and not completely without reason, from groups of people who are willing to give the extra time re- 
quired or else have not served on another committee recently, rather than from groups of people who are well qualified for the particular assignment.

6. Some staff members prefer to carry out routine work at their desks than to "fool around on committee work."

7. Committee meetings occupy staff time and attention which cannot easily be spared from desk work. Further, getting committee members to avoid letting persuasive individuals dominate their thinking is sometimes difficult.

8. Due to a limited perspective, committees may screen for obvious paper qualifications rather than for potential library contributions.

9. Certain search and screen committees are said to select not the best candidate, but instead, the candidate who displeases no one.

10. Often individual committee members with vested interests view candidates primarily from the vantage point of expected personal interaction rather than from a more broadly based frame of reference. This situation leads to the charge that these committees react emotionally, not logically.

11. Many search and screen committees have the limitations of other committees in diffusing responsibility and slowing down the selection process.

12. Administrators are presumed to be free to accept or reject committee recommendations. In practice, however, they may not be as free as assumed to reject them.

13. If administrators fail to act expeditiously or wisely on committee recommendations, the result is likely to be unsuccessful.

\section{ConCLusion}

Once started, use of search and screen committees is difficult for administrators to stop, even for a single case. Returning to traditional approaches will bring considerable staff criticism and will represent a renunciation of democratic administration. Of course, the same thing can be said for other aspects of participatory management as well.

Are university library search and screen committees generally useful? How can we assess their performance? Sufficient time has not yet elapsed for a firm evaluation of their success or failure. Surely, we shall see more of them in the future. They will be continued in order to meet the need for justifying appointments to an increasing variety of agencies, groups, and individuals. Equally important is the relationship of the committee concept to the increasingly popular concept of participatory management. As a mode of operational management, the participatory concept has gained popularity for both libraries and other university units. As long as the trend to participatory management continues, search and screen committees will flourish, even in the absence of reliable and objective determinations of their usefulness.

\section{REFERENCES}

1. Richard A. Kaplowitz, Selecting Academic Administrators: The Search Committee (Washington, D.C.: American Council on Education, 1973).

2. Richard Sommerfeld and Donna Nagely, "Seek and Ye Shall Find: The Organization and Conduct of a Search Committee," Jour- nal of Higher Education 45:239-52 (April 1974).

3. Louise Galloway, "Academic Librarians Participate in the Selection of the Director of Libraries," College \& Research Libraries 33: 220-27 (May 1972).

4. E. G. Bennis, "Searching for the Perfect 
University President, with Editorial Comment and Discussion," Atlantic 227:4, 3944 (April 1971); 32-35 (June 1971).

5. Paul C. Reinert, "The Problem with Search Committees," College Management 9:10-11, 39 (Feb. 1974).

6. Paul Strohm, "Faculty Search Committees and Review Committees: What to Do until the Bargaining Agent Comes," American Association of University Professors Bulletin 60:288-90 (Sept. 1974).

7. Responses were received in the spring of 1974 through January 1975 from the following: Phillip Howard, Oakland Univ. Library, Oakland, Mich.; James Govan, Univ. of North Carolina Library, Chapel Hill; Howard Rovelstad, Univ. of Maryland Library, College Park; Raymond A. Bohling, Univ. of Minnesota Twin Cities Library, Minneapolis; Richard E. Chapin, Michigan State Univ. Libraries, East Lansing; Richard W. Boss, Univ. of Tennessee Library, Knoxville; Marilyn O'Hair, Univ. of Albuquerque Center for Learning and Information Resources, Albuquerque, N.M.; David Kaser, Graduate Library School, Indiana Univ., Bloomington; Warren Owens, Univ. of Idaho Library,
Moscow; Jane G. Flener, Univ. of California Library, Berkeley; John K. Mayeski, Univ. of Washington Libraries, Seattle; C. James Schmidt, State Univ. of New York at Albany Library; Janet T. Paulk, Emory Univ. Library, Atlanta, Ga.; W. David Laird, Univ. of Arizona Library, Tucson; Joseph Jeffs, Georgetown Univ. Library, Washington, D.C.; James M. Dyke, New Mexico State Univ. Library, Las Cruces; Frederick Duda, Columbia Univ. Libraries, New York; Gay D. Henderson, Wright State Univ. Library, Dayton, Ohio; Robert H. DeWitt, Colorado State Univ. Library, Fort Collins; Franklin Long, Univ. of Notre Dame Library, Notre Dame, Ind.; Pearce S. Grove, Eastern New Mexico Univ. Library, Portales; Jay Lucker, Princeton Univ. Library, Princeton, N.J.; Robert H. Muller, Queens College Library, New York; Ben Jacobson, Northwestern Univ. Library, Evanston, Ill.; Robert K. Johnson, Univ. of Arizona Graduate Library School, Tucson; Richard L. Snyder, Drexel Univ. Library, Philadelphia, Pa.

8. Bennis, "Searching for the Perfect University President." 